\title{
Values in Repair
}

\section{${ }^{1}$ Lara Houston, ${ }^{1}$ Steven J. Jackson, ${ }^{2}$ Daniela K. Rosner, ${ }^{1}$ Syed Ishtiaque Ahmed, ${ }^{3}$ Meg Young, ${ }^{1}$ Laewoo Kang}

\author{
${ }^{1}$ Information Science \\ Cornell University \\ Ithaca, USA \\ $\{$ lh573, sjj54, sa738\} \\ @cornell.edu
}

\author{
${ }^{2}$ Human-Centered Design \\ and Engineering \\ University of Washington \\ Seattle, USA \\ dkrosner@uw.edu
}

\author{
${ }^{3}$ Information School \\ University of Washington \\ Seattle, USA \\ megyoung@uw.edu
}

\begin{abstract}
This paper examines the question of "values in repair" - the distinct forms of meaning and care that may be built into human-technology interactions through individual and collective acts of repair. Our work draws on research in HCI and the social sciences and findings from ethnographic studies in four sites - two amateur "fixers" collectives" in Brooklyn and Seattle, USA and two mobile phone repair communities in Uganda and Bangladesh - to advance two arguments. First, studies of repair account for new sites and processes of value that differ from those appearing at HCI's better-studied moments of design and use. Second, repair may embed modes of human interaction with technology and with each other in ways that surface values as contingent and ongoing accomplishments, suggesting ongoing processes of valuation that can never be fully fixed or commoditized. These insights help HCI account for human relationships to technology built into the world through repair.
\end{abstract}

\section{Author Keywords}

Repair; maintenance; design; values; ethnography.

\section{ACM Classification Keywords}

H. 1. 2. Human Factors

\section{INTRODUCTION}

A growing body of scholarship in HCI and the social sciences has called attention to the problem of "values in design": the myriad ways in which social and ethical concerns may be built into and out of artifacts, systems, and infrastructures through the process of design. Parallel work in science and technology studies has emphasized the embedding of values in larger forms of infrastructure and its consequences for deep social concerns around the distribution of power, knowledge, and authority in technically mediated social orders [5,36]. HCI scholars have brought these concerns back to the work of design

Permission to make digital or hard copies of all or part of this work for personal or classroom use is granted without fee provided that copies are not made or distributed for profit or commercial advantage and that copies bear this notice and the full citation on the first page. Copyrights for components of this work owned by others than the author(s) must be honored. Abstracting with credit is permitted. To copy otherwise, or republish, to post on servers or to redistribute to lists, requires prior specific permission and/or a fee. Request permissions from Permissions@acm.org.

CHI'16, May $07-12,2016$, San Jose, CA, USA

Copyright is held by the owner/author(s). Publication rights licensed to ACM.

ACM 978-1-4503-3362-7/16/05 ..\$15.00

DOI: http://dx.doi.org/10.1145/2858036.2858470 itself, advocating for design approaches that make explicit and systematic attention to values a core feature and contribution of HCI analysis and design. [2,6,15,17].

Our research extends this work by tackling the related but distinct problem of "values in repair": the forms and processes of value grounded in the ongoing work of fixing and maintaining the objects and systems around us. From this standpoint, questions of value in and around objects don't stop at moments of design and adoption, but extend to the long and rich history of relations through which worlds of human-computer interaction are sustained and held together. We keep our technologies going through acts of repair, from on-the-fly improvisations to faithful restorations. Just as values may be embedded in and through design, alternate processes of valuation may be set in motion through repair. This points us to different sites and agents of technological work: from HCI's usual suspects of designers and users, to a broader and often overlooked cast of actors and activities also central to human-computer interaction (at least where those interactions are sustained through time). It also reopens the question of value itself, and redirects HCI attention to the ongoing process by which value (and valuation) are achieved, sustained, and evolved through time in real-world computing environments.

Our paper builds on HCI traditions of value-centered analysis and a small but growing body of HCI and social science work dedicated to problems of maintenance and repair. Reporting on larger programs of ethnographic fieldwork with "fixer" movements in Brooklyn and Seattle and mobile phone repair workers in Uganda and Bangladesh, we make two central contributions. The first concerns the forms of value to be found in work and interaction surrounding the practice of technology repair in both amateur and livelihood communities. We show how systems of value originating in industrialized production meet local ecologies of care and expertise, where different moral relations and imperatives may unfold. We also explore values that draw people to repair, ranging from the economic and personal to the social and environmental: people choose to fix (or not) the objects around them for a wide variety of reasons, many of which have little to do with the instrumental "means-ends" logics central to 
standard HCI discussions around technology use and design.

Our second contribution concerns the nature (rather than the content) of the values so discovered. In particular, we show how repair can help us reorient how we think about values, from static achievement or fixed set of affordances (a position we'll describe as the "commodity fiction" of value) towards a more fluid and emergent model that treats value as an active and ongoing process. We understand valuation as the processes through which something is rendered important, or treated as worthy or useful, and values as moments where these broader processes become stabilized. From this perspective, acts of repair may extend but also enliven the landscape of things, building forms of meaning and attachment that help thicken human relationships to technology. Generic manufactured objects may be deepened or ennobled through repair, adding affective and social valences. Within an industrial and consumption-centered economy, new forms of durability can be achieved, and things meant to be discarded can be turned into things to be cared for and saved. At the same time, repair can change its human participants, transforming "mere users" into something slightly more, better versed and engaged with the object worlds around them. In short, repair may support ongoing forms of valuation that continue to unfold through the lifetime of our objects, reshaping values and meanings "originally" made durable through design.

This paper begins by reviewing parallel but largely separate bodies of work on repair and values in HCI. We track how early theoretical work treats each of these themes, and how more recent scholarship has reoriented and extended these claims. We then turn to vignettes from our four empirical sites in order to make two distinct contributions: first, to show how HCI discussions of value can be usefully extended beyond moments of design into moments of breakdown and repair; and second, to show how values in repair (and indeed other HCI contexts) are better conceived as processes rather than things: in effect, verbs rather than nouns. We conclude by discussing implications of our findings for wider HCI research and practice, and how attending to values (and valuation) in repair may open up new theoretical and empirical terrains for the field.

\section{HCI AND REPAIR}

While HCI scholarship has accorded vastly more attention to practices of technology design and adoption, questions of maintenance and repair are not wholly foreign to the field. Pragmatist and ethnomethodological traditions of $\mathrm{HCI}$ scholarship have long called attention to the importance of breakdown and repair as crucial but understudied moments in the life of technological objects, systems, and social interaction more generally. Breakdowns of (social) order and expectation hold a special place in American pragmatist traditions of social science, accounting most famously for the separation of thought and consciousness from more rote patterns of habit and routine that structure human interactions with the world [8,28]. The same instinct animates mid-century work in the American social sciences, from the Chicago School sociology of Hughes and Strauss [22,39] to Bateson's cybernetics [3], to traditions of ethnomethodology and conversation analysis [2,20,35] which are pragmatism's most obvious jumping off point into HCI. In contrast to their structural and/or functionalist social science competitors, these pragmatist traditions feature breakdown and repair as variously: a) ever-present realities of the social orders we engage; $b$ ) engines for learning, change, and adjustment across situation, difference, and context; and c) methods for surfacing the tacit and hidden features of social life in its smoothly functioning form.

The few extended empirical studies of repair in the HCI canon follow directly from this pragmatist tradition. A leading example is Julian Orr's book-length ethnography of Xerox repair technicians, [31] which calls into sharp relief the contingent nature of repair work, and the forms of collaboration required to diagnose and resolve the myriad forms of breakdown that routinely challenge and undermine effective human-computer interaction. As Suchman [40] famously demonstrated, these breakdowns also posed deep challenges to models of thought and action then dominant in Artificial Intelligence, necessitating a sea change from "planning" to "situated action" as the dominant mode and challenge of HCI work. Building on the same pragmatist foundation, influential work by Star and Ruhleder has noted the tendency of functioning infrastructure to disappear, reappearing only at moments of breakdown [37]. Subsequent work in infrastructure studies and HCI has articulated the significance of tensions and breakdowns as generative, even formative, moments in the emergence of new infrastructural systems and practices [32].

More recent work has extended these insights, moving beyond the organizationally bound worlds of the Xerox repair technicians studied by Orr and Suchman. Rosner et al. [34] and Jackson [24] have shown how technology breakdown and repair may expose facets of humancomputer interaction that exceed or frustrate design or engineering-centered expectations, and reveal dimensions of human-technology relations obscured under the field's traditional emphasis on design. Ethnographic projects in Namibia [26], Uganda [21], Kenya [43] and Bangladesh [25] have explored the nature and operation of mobile phone repair worlds in the global South, outlining forms of collaboration, innovation, value, and exchange through which technical infrastructures are sustained and extended. This growing body of scholarship takes sites of amateur and informal repair work seriously as skilled spaces of knowledge production and transmission. A separate body of work in collapse informatics has sought to reorient HCI design efforts from a future predicated on growth towards one marked by the breakdown, disruption, and contraction of existing social, technical and environmental systems 
[41]. These themes connect in turn to a growing body of analytic and design-based work in sustainable HCI that has considered the field's relationship to problems of environmental change and sustainability (see inter alia $[4,9,10])$.

Our work is heavily indebted to these prior bodies of HCI work. Our arguments draw on the recognition that breakdown is everyday rather than exceptional, and that the recuperative processes of repair are central to the maintenance of social and material orders across time. Insights from the HCI repair canon around the contingent and situated nature of repair work and the impossibility of its full encompassing within predictable plans of action contributes to our re-specification of "values" as processes of valuation. Finally, our case also points to the deep material embedding of repair, and its reliance on sometimes tacit or skill-based knowledges that may be difficult to convey through the abstractions of formal and linguistic description. As a consequence, stories loom large in the empirical accounts that follow; like Orr's technicians talking about machines is a crucial part of the sensemaking that surrounds and supports repair work [31].

\section{VALUES AND DESIGN}

Since the early 1990s, discussions of value within the HCI community have called attention to the "social, moral, and political consequences" of design practices [14,18]. Mirroring growing recognition of the social responsibilities of technologists more generally - marked for example by the founding of Computer Professionals for Social Responsibility in 1983 - the new "values" scholarship sought to call attention to design as an inherently value laden endeavor, and offer specific strategies by which the often tacit nature of values in design work could be more carefully and systematically accounted for.

In the early 1990s, Friedman, Nissenbaum and others opened calls for value-based approaches that were oriented to producing technological systems that were "good" to use in a moral as well as a functional sense [18]. Working on problems ranging from bias in computer architectures and search engines to the challenges of designing for user autonomy [18,19] and developing in counterpoint with related work in computer ethics, social informatics, CSCW, and participatory design, value sensitive research sought to integrate ethical concerns and socio-technical analyses directly into the process of design itself [16]. An influential variant of this work was developed across a series of articles in the 1990s and early 2000s by Friedman, Borning and others under the heading of "Value Sensitive Design" (VSD).

VSD was intended as a methodological framework to ensure structured and systematic attention to values within processes of design [15-17]. VSD is defined as a tripartite methodology enfolding conceptual enquiry (such as scoping values and identifying primary and secondary stakeholders), empirical enquiry (including ascertaining real-world preferences and attitudes among actors), and technical enquiry (the development and/or critical analysis of the technology itself) [17]. Iterations between these forms of enquiry present opportunities for embodying values in the design of individual systems or artifacts. At its core VSD seeks to account for and protect human values: "what a person or group of people consider important in life" [17, p.70]. While twelve "universal" values are explicitly named within early VSD work (including privacy, autonomy, and freedom from bias), Friedman et al. emphasize that these may take on different forms in particular times and places, and that other values may also be located and operationalized in and through VSD methodologies.

In the early 2000s, Flanagan, Howe and Nissenbaum advanced a parallel values in design framework, arguing once again for the moral role and responsibility of design and urging designers to engage their work as a "form of political or moral activism" [11, p.323]. Flanagan et al. discerned three forms of activity used to methodically embody values in design - discovery, translation and verification - which once again relied on the integration of technical, philosophical and empirical modes of enquiry [11]. Values could be embodied in systems or artifacts in three ways: through direct visual representations within the design itself; through its "material" affordances (the practices that a system or artifact enables or hinders) and within a wider situation where values "emerge indirectly as a property of the system's interaction with the contextual setting in which it operates" [11, p.345].

These values-based approaches have proved highly generative, being taken up in HCI research ranging from the security of wireless implantable medical devices [7] and the values of computational modelers [12], to homeless young people's experiences with information technology [42] and the development of co-design spaces [44]. The impact of this early values work is also reflected in initiatives such as the Values In Design (VID) Council, created in 2010 by Helen Nissenbaum, bringing together social scientists and designers under the Future of Internet Architectures project. A series of values in design workshops convened by Nissenbaum and Bowker have continued to renew and reset the agenda for values work in the field.

Generative critiques have reoriented this core methodological literature, questioning the specification and scoping of values themselves: for example, as universal or particular. Le Dantec et al. [6] locate VSD's twelve "universal" values as commitments arguably specific to computing cultures in Northern liberal democracies. They observe that this heuristic "privileges a discursive definition of values over values that may be discovered or encountered through investigation" [p.1141]. Instead, they argue VSD should encourage open-ended and exploratory empirical engagement with sites for design, in order to 
uncover local values that are appropriate to this specific context, taking care to distinguish between the values of designers and stakeholders [6]. Alsheikh et al. address similar concerns in their work on technology use in long distance relationships, highlighting how the privacy of the family (rather than the individual) is central within an Arab cultural context [1]. Knobel and Bowker [29] have explored forms of "cultural valence" which may imbalance global representations in and through technology, observing how a Google search for "Cameroon" produced exactly zero page one results emanating from the country itself. Reflecting on next steps for VSD, Borning and Muller [4] respond by arguing for a pluralist position, where no claims are made for the universality or specificity of values, instead leaving them open for empirical researchers to take up.

A second point of debate concerns the ontological status of values within wider interactional environments. JafariNaimi et al. [27] have argued that the definition of values as universal properties "emphasizes the identification of values rather than their service in design situations" [p.93]. This leads to an "identify/apply logic," in which scholars aim to find and define relevant values so that they may be applied more comprehensively to design practice. But JafariNaimi et al. argue that values are always surfaced in action: "practicing designers... make sense of values not at remove, as in scholarship, but in the oftenconfused design situations in which value has value" [p.93]. Similar insights can be drawn from science and technology studies: for example, Lepawsky and Mather's tracing of the movement of e-waste from Canada to Bangladesh, which discovers not waste but re-use, as discarded artifacts are disassembled and remade into other things [30]. This causes the authors to turn from noun to verb in their ontological reframing, asking "what we might learn if we followed actions; if we studied not waste and value, but wasting and valuing' [p.247].

In sum, value-centered approaches have made real and generative contributions to HCI theory and practice, not least by adding an explicitly ethical layer to HCI's traditional design orientation. More recent work has extended this early values work in two directions: first, away from ideas of "universal" human values and towards more specific questions of values in situ; and second, towards the recognition of value as a culturally organized process that is produced and reproduced through action. Our work shares this orientation, and approaches questions of value as an (inter)active and ongoing accomplishment, rather than a fixed stock of ethical "things" in the world - a position we describe after Foucault [13] as the "commodity fiction" of value. When played out at the global scale, this in turn lines up with other emerging HCI research programs - for example, around "postcolonial computing" [23] which attempts to situate these questions of difference within wider political discourses of technology design and manufacture between the global North and South. It also aligns well with investigations that take seriously the proposition that questions of value and valuation in and through technology are never fully fixed and answered through design, but may persist across the myriad processes by which technologies unfold and are sustained within the contexts and lifeworlds around them. This leads us to the ethical question(s) of repair, and the empirical studies that follow.

\section{METHODS}

This paper is part of a collaborative project undertaken by the authors to generate comparative insights about the values and processes of valuation surfaced in repair, an important contribution given the single-case nature of prior work in this area. We bring together four different repair sites: firstly, two amateur fixers' groups located in the USA: the Fixers' Collective in Brooklyn, New York and the Northeast Seattle Fixers' Collective in Seattle, Washington, and secondly, two mobile phone "repair worlds" [26] in Kampala, Uganda and Dhaka, Bangladesh.

All four sites were the subject of deep and sustained ethnographic engagement by one or more of the authors, including participant observation, the "hands on" learning of embodied repair skills, interviewing, photography and video recording (as a supplementary material). Interviews, field notes and video recordings were transcribed and coded based on grounded theory analysis [38]. Regular fieldwork visits to the Brooklyn-based Fixers' Collective began in November 2012 while engagement with the Northeast Seattle Fixers' Collective began in March of 2015; both are still ongoing. The Ugandan study draws on six months' ethnographic fieldwork spanning a three-year period from October 2010 to September 2012, while the Bangladeshi study was undertaken over a four-month period in 2013. All participants have been assigned pseudonyms.

While these projects began in partial independence and range in form and type, all of the sites demonstrated the continual negotiation of values in repair and involved analyses significantly shaped by shared theoretical foundations (notably pragmatist and ethnomethdological traditions of HCI work). The case vignettes that follow are representative of key themes surfaced within these larger bodies of ethnographic work. Our first case pairing speaks to the situated action of repair in Northern, amateur, activist repair sites, while the second Southern case pairing deals with wider social valuations of repair.

\section{AMATEUR REPAIR IN NEW YORK AND SEATTLE}

Our first two cases emerge from the small but rapidly growing amateur repair movement developing in parallel in Europe and North America. In 2009, organizers in Berkeley, Amsterdam and New York separately launched public events to help local residents fix (and learn to fix) their broken consumer appliances. The vignettes that follow demonstrate the values of collaboration and learning that frequently characterize and support ongoing participation in this space. They also however reveal the presence of other 
systems of valuation - including socially coded relations of expertise and sometimes gender - that may also mark and inflect these spaces. Our fieldwork highlights how these processes serve to legitimate certain aesthetics and practices of repair while limiting or undermining others, in ways that both expand and limit the reach and impact of repair practice in such settings.

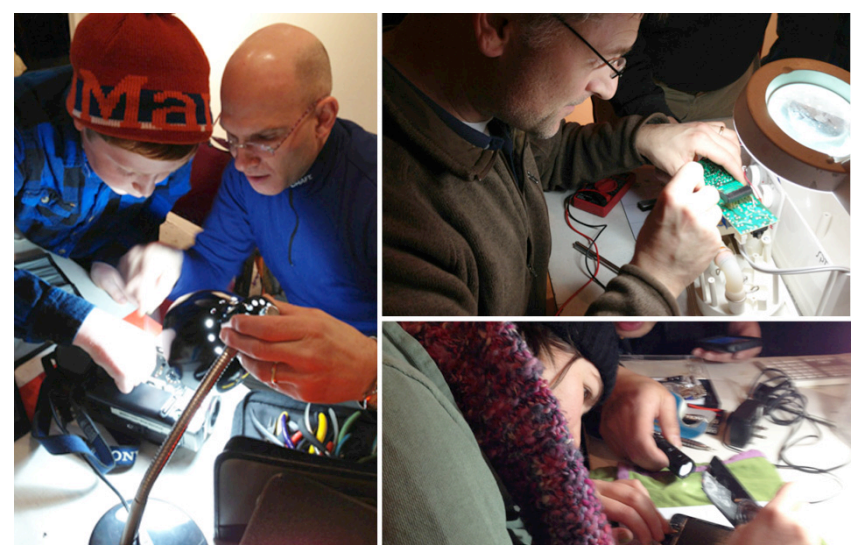

Figure 1: Repairs underway at the Fixers' Collective NYC, March 2015

\section{Fixers' Collective, Brooklyn}

Our first case involves the Fixers' Collective, an amateur repair organization that has since 2009 , met the third Thursday of every month at the Proteus Gowanus gallery in Brooklyn, New York. With roots in an earlier installation called "Mend" (2008), and drawing inspiration and resources from groups like iFixit and the Repair Café movement in Europe and beyond, the group's goal is to provide a public and collaborative space where repair skills can be practiced, shared, and supported. On any given night, the group attracts an eclectic cast of participants and objects. These include regulars with specific repair skills to offer (designated within the group as "master fixers"). It also includes occasional or one-off participants ranging in age from 8 to 80 , all of whom are invited to bring items in need of repair. Objects repaired by the group run the full gamut from household items (lamps, toasters, clothing, etc.) to consumer electronics. Over the course of our fieldwork organizers and participants emphasized the group's role in the transmission of repair skill and knowledge, and note a distinction between their activities and a simple drop-off repair operation: in the Fixers' Collective, participants are expected to actually fix; to join with other participants and the master fixers in learning and performing repair operations themselves. The vignettes that follow illustrate both the importance and the complexity surrounding this hands-on and collaborative ideal.

One February evening in 2014, Rita a female participant in her mid-20s arrives at the Fixers' Collective with a nonfunctioning MacBook Pro. She explains that the laptop is hers, that water was accidentally spilled on the keyboard some weeks ago, and since then it won't turn on when the power button is pressed. Following her explanation a master fixer called Tom looks over the laptop. He tells her they should start by finding the model number, and looks for a repair manual or other information online. He points her to the model number engraved on the bottom of the backplate. As she reads him the number, he searches online, finding a hit on the iFixit website - a group the Fixers' Collective regularly depends on for online resources, spare parts, and specialized tools. Having located the appropriate resource, Tom and Rita now work together to disassemble the laptop, following the instructions laid out on the iFixit site. Upon removing the front plate, Tom plugs the power cable back into the charging slot. The indicator light turns green. "Oh, it's going on now. It didn't go on before!" Rita exclaims. She presses the power button, but the laptop still won't boot up. Tom suggests removing the RAM memory, in case the units have been damaged by water. They work their way through a separate set of instructions on the iFixit site describing $R A M$ removal, with Rita holding the front plate as Tom first locates and them removes the RAM cards.

As they are working, Mike (another master fixer with more experience in laptops) wanders by to join the conversation. "Do you know what this indicator means?" he asks. "It means that the processor is inactive," Tom replies. After another 20 minutes of discussion and a variety of trials, the MacBook suddenly makes a beeping noise and starts booting. Everyone around reacts with surprise and pleasure. Mike points to the other fixer and exclaims "You reset the P-RAM!" Tom smiles and responds, "Right! Yeah, yeah. That's probably what I did. Because it automatically turns on everything." "So what was the problem?" Rita asks. "We're not sure," Tom explains. "It could be a bad RAM slot. I put one chip in the slot, and got a blinking sleep light. Then I put the same chip in the other slot and reset the P-RAM, so...". As this explanation is concluding, the laptop finishes its boot sequence, and the screen changes to a picture of Rita standing in front of a bridge. She exclaims in pleasure, and smiles are exchanged all around.

The scene above embodies the principles of collaboration and learning that are central to the Fixers' Collective and related organizations in the wider "fixer" movement. This is in some ways an ideal case: the participant shows up with a problem, and members of the group work with the participant and with each other to assemble relevant resources and expertise (including those located in online sources). Rita walks away with a functioning laptop, a better understanding of how it works, and possibly with a story and memory now attached to the device itself. Educated guesses are made, fixes are attempted, and at some point in the process of trial and error produces a positive result. Along the way, small bits of understanding and belonging are also produced, through the shared puzzle of the broken laptop. The small victory of the waterdamaged laptop becomes a point of hope and connection among participants and fixers alike, and buoys the group 
through other not-always-so-successful attempts. For of course, not all interactions end so happily. In many instances, devices are found to be unfixable, and master fixers advise participants on the best way of disposing of broken items (which may include recycling or salvaging parts for other purposes). In others, participants stand idly by, as expertise and other forms of difference reassert themselves, and the task of diagnosing and responding to broken objects returns to those with longer experience or specific training in this space. This tension between expertise, collaboration and learning figures more centrally in the second vignette shared below.

\section{Northeast Seattle Fixers' Collective}

The Seattle Fixers' Collective developed in 2011, after a former engineer read about the Brooklyn-based Fixers' Collective and decided to start one locally, prompted by the breakdown of his two-week-old salad spinner which could not be fixed due to embedded, inaccessible screws. Two years later, the Northeast Seattle Tool Library - a community-run organization that lends tools much like libraries lend books - began its own Collective as a way to meet their sustainability mission and increase membership. Today the group meets monthly for 3 hours in the workshop space of the Northeast Seattle Tool Library, which is run out of a standalone building in a church lot. Inside, shelves of tools lead to a check-out at the front; a large, long work table fills the space in the back. Most days, fixers help attendees from the neighborhood and members of the tool library repair broken household items, including shovels, lawn mowers, and food processors. When few or no attendees come to a session, the fixers tend to stay the full three hours anyway, often tinkering with items from the tool library inventory in need of repair. However, the dynamic of control between fixers and attendees reveals some important concerns for authorship and visibility, impacted by who shows up to help fix. Most fixers are white men in retirement from engineering jobs. The following vignette illustrates the limits and contours of collaborative repair.

In May 2015, a woman named Kay enters building with a broken lamp and a shattered pot lid. Kay is an effervescent woman in her early sixties with silver-blonde hair. She is a longtime volunteer at the Tool Library, and has been to the Fixers' Collective many times. Soldering her broken lamp back together had been straightforward, she says, so she is excited to start a more complicated repair-a cooking pot lid. Alex, a tall, talkative fixer in his fifties, approaches her to help. Kay dropped the glass lid at home, leaving her with only its metal rim and a handle that had been screwed into the glass. She has an aluminum turkey-basting pan she hopes to use as raw material to create a new top for the lid. Once he learns of Kay's plans, Alex becomes doubtful. "You want to fix this?" he exclaims holding up the lid in disgust. He goes on, however, to help her cut out a piece of aluminum to fit the metal rim, using rubber wedges and a mallet to pound it into its crevices without tearing the aluminum's surface.

There is an open question of how to get the aluminum to stay attached to the lid. Alex adamantly advises her to use bathtub caulk, saying "she wouldn't eat off of it" so there is nothing to worry about. Another fixer, Bo, is much more concerned, warning Kay that she needs to make sure it would be fire rated silicone, if she used it at all, and that he doesn't think it is a good idea. "Don't put it in the oven. This one never goes in the oven," Bo directs. When Kay steps outside Alex begins making veiled criticisms of the project. "It will be a piece of art, knowing Kay. A piece of recycling." Then, he says something a bit more judgmental: "It's up to Kay if she wants to show her friends or not." I stand with Alex, considering ways to attach the lid handle to the top. Kay's aluminum pan had a hard wire undergirding; I think that Kay wants to cut and use it as an exoskeleton to attach the handle securely. Alex disagrees, saying that Kay wants that part to "be waste." Later, when Alex leaves, Kay stands talking with me. Kay says she had wanted to use the heavy-gauge wire, but that "Alex was not going for it."

Here, the fixer evaluates Kay's repair in unflattering terms. He suggests that the repair is something that she should be ashamed of, and should possibly not show to her friends. Kay's fix restores function to the pot-she looks specifically for food-safe materials so she can use the pot lid as she did before. However, the appeal to restoring function to an object stands in contrast to an appreciation for tidy and professional-grade workmanship. Alex's criticism stems from a sense that the work is inelegant or embarrassing in form. Alex tries to take the repair in a different direction than the one that Kay had intended. Counter to the many electronic devices that that come into the Collective, the workmanship of repair for this pot lid is necessarily fully exposed, open to visual critique and technical interrogation. For other fixers and participants, a repair and its analysis carries traces of its repairer, and his or her competencies. This dynamic reflects other cases of repair that we observed, where male fixers exercised authorship over repairs, asserting forms of technical mastery historically equated to the assumed pleasures men attain through technical work. Participation in this community of amateur invites confronting cultures of masculinity - and associated questions of visibility developing in and around repair.

\section{Bounding participation}

The values of collaboration and learning are central to the two Fixers' Collectives and they underpin two significant organizational ideals. The development of collective bodies of knowledge and skills around repair prevents the wasting of objects that might still have a useful life; extending the use of resources, and deferring replacement purchases for the benefit of the environment. Secondly, learning through participation in repair increases the sense of agency that 
members of the public have over the objects in their lives. Fixers' Collectives attempt to normalize careful, technical and materially engaged ways of knowing and living with everyday consumer objects. Appeals to collaboration and learning are used by repair organizations to distinguish their free events from traditional paid-for, drop-off repair services. Participation-value replaces exchange-value.

Within the two vignettes we see how values, rather than stable properties of organizations, become negotiated in action, as processes of valuation unfold in repair. In the first vignette Rita, the owner of the MacBook Pro, and the two master fixers Tom and Mike work together in an open exchange within the unfolding process of diagnosing and repairing the machine: a situation where everybody learns something. Skills and knowledges of repair are assembled and shared between fixers and participants, in ways driven by shared motivations and affective connection. In these interactions, social meanings are also being negotiated and passed on, about what it means to shape repair practices, the boundaries of participation and performances of mastery.

Collaboration and learning play out quite differently in the second vignette, as tensions emerge between the valuations of master fixer Alex and participant Kay in the repair of a broken pot lid. Valuing is a central dimension of repair, as practitioners first make sense of whether artifacts are "worth" repairing in a particular social and material context, and secondly, as they work to preserve value by restoring or transforming artifacts before they fall into the category of waste. Although Kay believes in the pot lid repair, fixer Alex maligns it as an example of "art" or "recycling" - leading to disagreements about how to take the repair forward, in the choice of materials and how to combine them. Authority is a central question: this exchange makes visible dynamics of control that shape the collaborative learning relationship between participants and master fixers. Processes of valuing are crucial to the ways that public participants and master fixers negotiate the social and material asymmetries of knowledge and skills inherent in the organization of these activist events. The gendered framing of repair here is particularly striking, as Alex performs an identity of mastery that reflects historical linkages between masculinities and repair [33].

\section{LIVELIHOOD REPAIR IN KAMPALA AND DHAKA}

Our second set of repair endeavors locate repair as part of livelihood communities in Kampala and Bangladesh. In these sites of mobile phone repair we find corporate systems of value and socioeconomic status confront the concerns and competencies of local fixing ecologies. Our fieldwork surfaced difficulties of valuation in the shifting material configuration of electronic devices, revealing moments where skilled technical work sits in tension with financial and social reward.

\section{Mobile Repair in Kampala, Uganda}

Within the mobile phone repair world of downtown Kampala, livelihood businesses predominate: technicians run their own informal and independent micro-enterprises, sometimes employing an assistant or apprentice. However, corporate actors are also represented, as four larger repair workshops maintain relationships of "authorization:" two with mobile manufacturers and two with mobile network providers. The following case explores tensions in the valuing of particular repair practices between these regimes of repair.

Sitting upstairs in an airy repair workshop one afternoon in September 2012, a technician describes how mobile repair is becoming more difficult. Peter works in a mobile dealership authorized to sell and repair two leading mobile brands: one European and the other East Asian. He juxtaposes two motherboards from the same European manufacturer and points out how the newer model has an on-board microphone, where the microphone pierces the motherboard with the component on one side and an output on the other. Peter explains that it can no longer be replaced using a soldering heat gun (called a "blower" for the way that it blows a stream of hot air), but needs an infra-red soldering station which he doesn't have access to. I remember seeing an independent technician replace this type of mic using a different technique called looping, and I show Peter the picture below. This skillful work involves soldering thin copper wires from the contacts on the motherboard to the contacts on the mic.

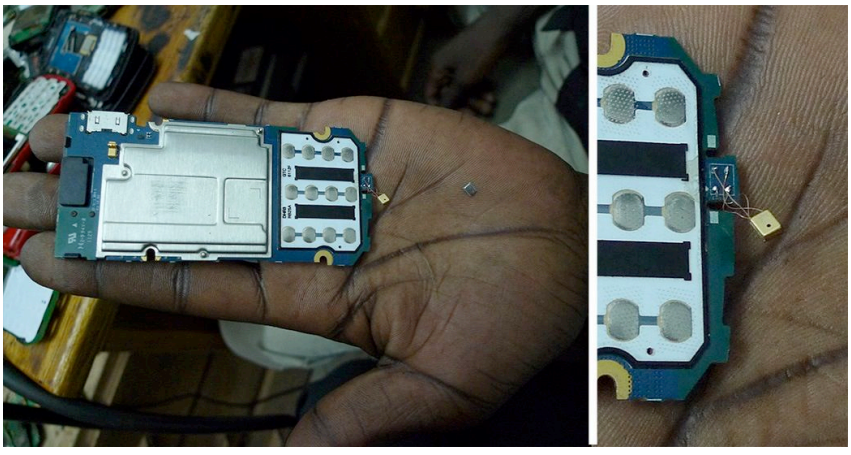

Figure 2: The discarded microphone is visible on Jason's palm. He has connected a replacement microphone using four copper wires, rather than mounting it on the motherboard, as can be seen in the magnified image, September, 2012.

Peter is unimpressed, describing looping as "just tampering" saying that "it creates noise in the circuit, it's unprofessional and doesn't last". He explains that if the phone was dropped, the loop would break and the customer would be back when the repair had failed... his company would never allow it. I ask Peter if looping has a place for those who want to extend the life of their phone, even for a short time. He replies no, "it's about your own standards," explaining that he wants to do quality work that makes him feel good and sleep well at night. But other standards are also at work here: this workshop was only authorized to a 
Level Two standard by the mobile manufacturer, meaning that Peter is unable to undertake any repairs of onboard components. This microphone repair was simply unable to be performed in the "authorized" way, in this workshop.

This vignette demonstrates the changing material forms between older and newer mobile handsets, even those made by the same manufacturer, raising vital questions for designers around repairability. Replacing a damaged microphone was once one of the easiest repairs for technicians in training; now it increasingly requires the specialist skill of looping. This vignette demonstrates how repairability does not simply index material affordances, but takes shape in relation to organizational contexts for repair, configurations of knowledge, embodied skills, and access to tools within "repair worlds" [26,34]. Crucially, this case illuminates the central role that values and processes of valuation have in negotiating the limits of repair practice.

Looping, for example is contested practice across authorized and independent sites. It has different material properties than the like-for-like replacement of a part: as a skilled technique it makes the phone function again, but it is more fallible than the original design and less safe in the case of a power surge. Peter devalues looping as "just tampering", framing it as an intervention that would not be legible or acceptable to his company's standards. This case reveals how relationships of authorization are one way in which corporate values in repair impact local repair worlds, as systems of value come down the corporate chain and meet the local ecology in Kampala.

In response to accusations of "just tampering," independent technicians argue that authorized workers "don't even repair". In Peter's case, authorized values in repair restrict his work to the replacement of non-integrated parts, rendering whole generations of handsets unfixable after the simple failure of a mic, or other on-board component (at least using any authorized technique). For independent technicians, authorized standards are a rejection of the idea that repair itself is a form of valuing in action, simply because the quality of the restoration work cannot meet original design specifications. Independent technicians value successful repairs above all else - firstly because customers only pay for working devices. Yet much more is happening here than simple functionalism: repairing "by any means" is understood by independent technicians as creative, improvisational and masterful work, which makes the most of materials, and is deeply connected to professional pride and identities of mastery in downtown Kampala.

\section{Mobile Repair in Dhaka, Bangladesh}

As with the Kampalan case, the mobile phone repair world in Dhaka consists of a range of workshops, including highend brand "authorized" workshops and informal, independent livelihood businesses. The educational background of repair workers ranges widely: some are engineers from low-ranking universities, others had graduated in unrelated disciplines, and a subset had very little or no educational background. Repair waste collectors, locally called "Bhangari," (from the Bangla word "bhanga," meaning broken) worked closely with repairers, visiting workshops to buy discarded electronic objects cheaply and selling them on at a higher price to Chinese recyclers. Our study surfaces uncertainties about the social status of repair workers in Bangladesh, taking the role of repair technicians and the economic valuation of waste materials performed by Bhangari waste collectors as counterpoints.

I meet Rimon a 35-year-old mobile phone repairer, in May 2013 at his workshop in a busy shopping mall in Dhaka. He explains that he comes from a very modest family and did not continue his education after the 9th grade, instead starting his career as an ornaments maker. He fell in love with a woman in his community, but her higher family status did not allow Rimon to propose to her, so he decided to change his profession to work with the latest electronic technologies, which at that time meant the repair of mobile phones. As a first step, he started working with one of his friends in an electrical workshop, and then he got an apprenticeship in a mobile repair shop and learned the basic techniques. At that point, he considered himself good enough to propose, but, it was too late; the woman he loved had already married somebody else. Rimon continued building his career in mobile phone repair, and he is now a renowned repairer with his own shop.

Like Rimon, we found that many of our participants switched jobs into mobile phone repair in order to upgrade their social status, yet many were still frustrated with the lower social status of repair compared to engineering. None of our participants wanted their children to be repairers: most of them wanted their children to be engineers or doctors. Wasim, a senior repairer in Gulistan Underground Market was sharing his frustration about this when he explained: "A lot of boys from good families cannot complete their education, and could easily come into the repair profession. The problem is nobody calls a repairer an "engineer". I have seen many engineers who know nothing, but just managed a certificate. They get better social status, while repairers are considered as 'service men'. This is unfortunate; some of our repairers could teach many things, even in the universities."

Yet even within the Dhaka repair world, the appreciation of academic education determines a repairer's place of work. Software repairers are more highly paid and valued than hardware technicians, because being able to read and write in English is a prerequisite for this work, whereas it is assumed that even an illiterate person can work with hardware. University graduates get jobs at the authorized service centers of multinational brands. As in our Kampalan repair site, we observed distinctions between the valuing of authorized and independent repair work. In Dhaka, 
independent repairers described authorized work as replacing rather than fixing components, which most of the independent repairers did not consider to be "actual repairing". They explained that technicians in the authorized workshops would often come to take help from the independent repairers, a practice that remained secret through financial contacts.

On the other hand, the Bhangari community is concerned about the value of the materials within the electronic waste that they buy. At the Bhangari shops, the collected objects are classified based on the residual components left on their motherboards. Lutfur, a senior Bhangari, does not differentiate between motherboards of different companies. Instead, he checks how many integrated chips the motherboards have. The condition of the motherboards also does not matter much to him. He looks at his weighing scale and tells me, "The only thing that matters is the weight."

These tensions in social status and value judgments present a broader socio-economic framework within which the livelihood repair communities of Bangladesh operate. The status of mobile phone repairers may be higher than the ornament makers, however, this is a reflection of the social appreciation of their expertise with electronic devices and not particularly of repair; something which becomes evident when they are compared with engineers. The knowledge, skills, and hard work of the repairers cannot lift them up to the level of the engineers. This distinction between professions, described by the repairers themselves, highlights the different values assigned to the work of building the new and repairing the old. Invisibility plays a dual role in repair, in that "good repairs" erase or minimize the evidence of breakdown (both in terms of aesthetics and functionality), while repair practitioners themselves inhabit backstage roles that come with low pay and low status, such as mobile phone repair in Dhaka.

When repair fails, value begins to fall away from an object: most notably use-value, but also other forms of affective attachment that exist between people and their possessions. The Bhangari waste collectors work to revive value from discarded motherboards by stripping and selling them in bulk. Here, value is framed solely in terms of the price by weight that the Chinese buyers will pay. At the same time, we see forms of valuation assigned to people, tied into the social status of repair. Forms of work are better and less regarded, with categories of work, such as waste collecting excluded even from the "technological" status that attracted Rimon to the profession.

\section{DISCUSSION}

The cases above make visible the specific embedding of repair across a variety of economic, social and material settings not usually considered together. This comparative framing enables us to point out both shared and divergent processes of valuation in repair. In all four of our sites, technicians, customers, master fixers and participants work towards the careful rejuvenation of objects and the restoration or preservation of their usefulness; from lowtech pot lids and the ubiquitous MacBook Pro to the many mobile handsets that are part of expanding infrastructures in Uganda and Bangladesh. At the same time these acts are enlivened by very different motivations and imperatives that move this discussion beyond the organizational settings highlighted in much of the HCI repair canon.

In our two amateur sites in the USA, working products are not the only ends: repair is made valuable as a collaborative activity centered around participation and shared learning, oriented towards producing different affective and practical relations to objects, illuminated most clearly in the New York case. New values are introduced through practices of repair: repairing together becomes a way to address the various concerns of master fixers and participants, including a sense of alienation from the workings of devices, wasteful consumption patterns and environmental damage. At the same time, the situated process of collaborative repair reveals competing understandings of what is worth repairing and how, particularly in the Seattle case, which points towards repair as a gendered framing.

In Kampala and Dhaka, we surface different regimes of value active within repair communities themselves and the wider social settings in which they operate. In Kampala, design impacts repair worlds not only through the material affordances of devices (values "embedded" in design), but in the way authorized values in repair limit particular forms of practice. In contrast, independent technicians see repair as a form of valuing in and of itself, where the limits of repair are defined by technicians' own skill and mastery. These findings are echoed in Dhaka, where we also see vast imbalances in credit and compensation allocated to repair versus those allocated to the production of new technologies through engineering. When technologies break down into "waste" materials, we see further retrenchment of value, as Bhangari waste collectors are denied even the "technological" status that repair work enjoys.

Using insights drawn from these four case vignettes, the first core contribution of this paper has been to highlight the centrality of values in repair, and to argue for repair as an important site through which values are achieved and maintained. Despite their many and important gains, we suggest that design-centered approaches to questions of value and technology may suffer precisely from a narrow or over-weighted orientation to design itself - and that this orientation reflects in turn a larger imbalance in the field that actively obscures and disadvantages the forms of work described here.

Our exploration of "values in repair" renders visible the social and collective organization of value, whether in amateur activist sites, or across livelihood repair communities. By examining the collective negotiation of values across four very different repair worlds, we have 
moved beyond the dominant relation in HCI values scholarship between a technological artifact and its single user. This suggests a different agenda for HCI work, firstly in continuing to take repair work seriously, but in addition, further exploring the way questions around value surface in how communities care for their technologies collectively. Our research pushes the values in design literature to move outward in scope to encompass new sites and actors that are not envisaged in current modes of evaluation, which focus narrowly on how well values have been "embodied" or "embedded" in design during the privileged moments of user adoption. Our work points to multiple and ongoing moments of adoption as items are recycled, resold gifted, shared and repaired together.

In addition, our case studies have shown that questions of value are central to how (and whether) objects are sustained over time, particularly in amateur and livelihood repair settings, which are relatively new areas to the HCI community $[25,26,33,34]$. Within different repair worlds, valuation may include the pleasure of an avocation, the building of community, a contribution to activist agendas, the pursuit of professional pride, in addition to economic reward. Values are clearly not settled at the point of design, but are repeatedly negotiated as objects wear, age, and malfunction, and are cared for (or not) by the removal of these traces and the resetting of broken parts. Our cases demonstrate the multifaceted nature of the values at stake in sustaining objects across time, opening up new avenues for exploration that move beyond calculations of the economic worth or sentimental value of an object to an individual, or the functionalist life cycle analyses of particular products.

By extension, this work questions the ontological status of values themselves, and how we understand their implications for social and political life: the second core contribution of this paper. Generative critiques of VSD and values in design methodologies such as Le Dantec et al. [6] have sought to question the framing of values as universal properties, arguing instead for the empirical exploration of particular design contexts in order to locate values relevant to users (rather than drawing primarily on analyst categories). Likewise JafariNaimi's more recent analysis [27] argues against a two-step "identify/apply" logic within values literature, proposing that values cannot be understood as prior properties outside of action.

Repair literatures offer analytic resources to advance these critical agendas: pragmatist and ethnomethodological influences have oriented the HCI repair canon towards breakdown and repair as everyday processes, in a world where shared understanding is contingent on ongoing collaborative interaction, including between humans and technologies [31,40]. Drawing on JafariNaimi et al. [27], work by Lepawsky and Mather on e-waste [30], and our own case studies, we argue that values are better conceptualized as processes of valuation. In this, we turn away from a "commodity fiction" of values [13] (a position where values are a fixed stock of things in the world, divorced from action). This change in focus emphasizes the contingent, ongoing processes through which things are rendered valuable in a wider social and material context.

We suggest that focusing on processes of valuation may be a generative theoretical and methodological shift for values in design scholarship, providing ways to address open questions in the literature about how, and whose, values are materialized within design practice [6,27]. Thinking in terms of processes rather than properties, it becomes clear that what values are materialized and how they are made visible are deeply intertwined issues. Our comparative work suggests the need to empirically engage with valuation as a situated and collective process unfolding within a particular context that includes sites and processes of design. Our cases also point towards conflicts between different regimes of value and valuation that often remain unresolved and require accounting for.

Accounting for repair practices as sites of valuation, we can begin to see broader programs of HCI design as ethical provocations and starting points rather than final words. Rather than determining final outcomes, design practices may be best conceived as social mechanisms by which a host of economic, social and material arrangements are born and set in motion, rather than definitively concluded. Our intention is not to suggest that values never stabilize, but rather that they continue to do so across the entire trajectory of the object(s) in question - a course that includes the forms of maintenance and repair by which objects are continually sustained and kept live. Approaching such processes as sites of valuation invites recognition of these stabilities as temporary outcomes of social and material change. Rather than universal properties of human subjects, valuations forge new relations. For HCI scholars seeking to expand our design practice and understand such interventions, this highlights the power of valuations to not only represent social and material orders but to help build them differently, enlivening new landscapes of technological development along the way.

\section{ACKNOWLEDGEMENTS}

Research for this paper was supported by funding from NSF Grant IIS-1422621, and the Intel Science and Technology Center for Social Computing.

\section{REFERENCES}

1. Tamara Alsheikh, Jennifer A. Rode, and Siân E. Lindley. 2011. (Whose) value-sensitive design: a study of long-distance relationships in an Arabic cultural context. Proceedings of the ACM 2011 conference on Computer supported cooperative work, ACM, 75-84.

2. Morgan G. Ames, Janet Go, Joseph 'Jofish' Kaye, and Mirjana Spasojevic. 2011. Understanding technology choices and values through social class. Proceedings of the ACM 2011 conference on Computer supported cooperative work, ACM, 55-64. 
3. Eli Blevis. 2007. Sustainable interaction design: invention \& disposal, renewal \& reuse. Proceedings of the SIGCHI conference on Human factors in computing systems, ACM, 503-512.

4. Alan Borning and Michael Muller. 2012. Next steps for value sensitive design. Proceedings of the SIGCHI Conference on Human Factors in Computing Systems, ACM, 1125-1134.

5. Geoffrey Bowker and Susan Leigh Star. 1999. Sorting things out: Classification and its consequences. MIT Press. Massachusetts, USA.

6. Christopher A. Le Dantec, Erika Shehan Poole, and Susan P. Wyche. 2009. Values as lived experience: evolving value sensitive design in support of value discovery. Proceedings of the SIGCHI conference on human factors in computing systems, ACM, 1141-1150.

7. Tamara Denning, Alan Borning, Batya Friedman, Brian T. Gill, Tadayoshi Kohno, and William H. Maisel. 2010. Patients, pacemakers, and implantable defibrillators: Human values and security for wireless implantable medical devices. Proceedings of the SIGCHI Conference on Human Factors in Computing Systems, ACM, 917926.

8. John Dewey. 1922. Human nature and conduct. Dover Edition. 2012 Print. Dover Publications. Mineola, USA.

9. Carl DiSalvo, Phoebe Sengers, and Hrönn Brynjarsdóttir. 2010. Mapping the landscape of sustainable HCI. Proceedings of the SIGCHI Conference on Human Factors in Computing Systems, ACM, 1975-1984.

10.Paul Dourish. 2010. HCI and environmental sustainability: the politics of design and the design of politics. Proceedings of the 8th ACM Conference on Designing Interactive Systems, ACM, 1-10.

11. Mary Flanagan, Daniel C. Howe, and Helen Nissenbaum. 2008. Embodying values in technology: Theory and practice. Information technology and moral philosophy. Jeroen Van Den Hoven and John Weckert (eds.) Cambridge University press, UK. 322-353.

12.Kenneth R. Fleischmann, William Wallace, and Justin M. Grimes. 2010. The values of computational modelers and professional codes of ethics: Results from a field study. System Sciences (HICSS), 2010 43rd Hawaii International Conference on, IEEE, 1-10.

13. Michel Foucault. 1980. Power/knowledge: Selected interviews and other writings, 1972-1977. Pantheon Books, New York.

14. Batya Friedman. 1990. Societal Issues and School Practices: An Ethnographic Investigation of the Social Context of School Computer Use. Annual Meeting of the American Educational Research Association. Boston. April 16-20. Retrieved 8 January 2015 from http://files.eric.ed.gov/fulltext/ED321740.pdf

15.Batya Friedman. 1996. Value-sensitive design. Interactions 3, 6: 16-23.

16. Batya Friedman and Peter H. Kahn Jr. 2003. Human values, ethics, and design. The Human-Computer
Interaction Handbook. Andrew Sears and Julie A. Jacko (eds.) L. Erlbaum Associates Publishers. Mahwah, USA. 1177-1201.

17. Batya Friedman, Peter H. Kahn, and Alan Borning. 2008. Value sensitive design and information systems. The Handbook of Information and Computer Ethics Kenneth E. Himma and Herman T. Tavani (eds.) Wiley, Hoboken, USA. 69-101.

18. Batya Friedman and Helen Nissenbaum. 1996. Bias in computer systems. ACM Transactions on Information Systems (TOIS) 14, 3: 330-347.

19. Batya Friedman and Helen Nissenbaum. 1997. Software agents and user autonomy. Proceedings of the first international conference on Autonomous agents, ACM, 466-469.

20.Harold Garfinkel. 1967. Studies in ethnomethodology. 1991 Print. Polity, Cambridge, UK.

21.Lara Houston. 2014. Inventive Infrastructure: An Exploration of Mobile Phone Repair Practices in Downtown Kampala, Uganda. PhD Dissertation. Lancaster University, Lancaster, UK.

22.Everett Cherrington Hughes. 1971. The sociological eye: Selected papers. 1984 Print. Transaction publishers. Herndon, USA.

23.Lilly Irani, Janet Vertesi, Paul Dourish, Kavita Philip, and Rebecca E. Grinter. 2010. Postcolonial computing: a lens on design and development. Proceedings of the SIGCHI Conference on Human Factors in Computing Systems, ACM, 1311-1320.

24.Steven J. Jackson. 2014. Rethinking Repair. In Media Technologies: Essays on Communication, Materiality, and Society Tarleton Gillespie, Pablo J. Boczkowski, Kirsten A. Foot (eds.) MIT Press, Cambridge, USA. 221-240.

25.Steven J. Jackson, Syed Ishtiaque Ahmed, and Md Rashidujjaman Rifat. 2014. Learning, innovation, and sustainability among mobile phone repairers in Dhaka, Bangladesh. Proceedings of the 2014 conference on Designing interactive systems, ACM, 905-914.

26. Steven J. Jackson, Alex Pompe, and Gabriel Krieshok. 2012. Repair worlds: maintenance, repair, and ICT for development in rural Namibia. Proceedings of the ACM 2012 conference on Computer Supported Cooperative Work, ACM, 107-116.

27. Nassim JafariNaimi, Lisa Nathan, and Ian Hargraves. 2015. Values as Hypotheses: The Service that Values Provide. Design Issues 31, 4.

28. William James. 1910. The Meaning of Truth. A Sequel to Pragmatism. Longmans, Green, and Company, New York, USA.

29. Cory Knobel and Geoffrey C. Bowker. 2011. Values in design. Communications of the ACM 54, 7: 26-28.

30.Josh Lepawsky and Charles Mather. 2011. From beginnings and endings to boundaries and edges: rethinking circulation and exchange through electronic waste. Area 43, 3: 242-249. 
31.Julian Orr. 1996. Talking About Machines: An ethnography of a modern job. Cornell University Press, Ithaca, USA.

32.David Ribes and Thomas A. Finholt. 2009. The long now of technology infrastructure: articulating tensions in development. Journal of the Association for Information Systems 10, 5: 5.

33.Daniela K. Rosner. 2014. Making citizens, reassembling devices: on gender and the development of contemporary public sites of repair in Northern California. Public Culture 26, 1 72: 51-77.

34.Daniela K. Rosner and Morgan Ames. 2014. Designing for repair?: infrastructures and materialities of breakdown. Proceedings of the 17th ACM conference on Computer supported cooperative work \& social computing, ACM, 319-331.

35. Harvey Sacks. 1992. Lectures on conversation. Gail Jefferson (ed.) 1995 Print. Blackwell, Malden, USA.

36.Susan Leigh Star and Geoffrey C. Bowker. 2007. Enacting silence: Residual categories as a challenge for ethics, information systems, and communication. Ethics and Information Technology 9, 4: 273-280.

37. Susan Leigh Star and Karen Ruhleder. 1996. Steps toward an ecology of infrastructure: Design and access for large information spaces. Information systems research 7, 1: 111-134.

38. Anselm Strauss and Juliet M. Corbin. 1997. Grounded theory in practice. Sage. Thousand Oaks, USA.
39. Anselm Leonard Strauss. 2008. Continual permutations of action. AldineTransaction. New Brunswick, USA.

40.Lucy A. Suchman. 1987. Plans and situated actions: the problem of human-machine communication. Cambridge University Press. Cambridge, UK.

41. Bill Tomlinson, M. Silberman, Donald Patterson, Yue Pan, and Eli Blevis. 2012. Collapse informatics: augmenting the sustainability \& ICT4D discourse in HCI. Proceedings of the SIGCHI Conference on Human Factors in Computing Systems, ACM, 655-664.

42.Jill Palzkill Woelfer, Amy Iverson, David G. Hendry, Batya Friedman, and Brian T. Gill. 2011. Improving the safety of homeless young people with mobile phones: Values, form and function. Proceedings of the SIGCHI Conference on Human Factors in Computing Systems, ACM, 1707-1716.

43. Susan Wyche. 2015. Exploring mobile phone and social media use in a Nairobi slum: a case for alternative approaches to design in ICTD. Proceedings of the Seventh International Conference on Information and Communication Technologies and Development, ACM, $1-8$.

44.Daisy Yoo, Alina Huldtgren, Jill Palzkill Woelfer, David G. Hendry, and Batya Friedman. 2013. A value sensitive action-reflection model: evolving a co-design space with stakeholder and designer prompts. Proceedings of the SIGCHI conference on human factors in computing systems, ACM, 419-428. 